\title{
Behavioural Observations of Adult-Child Pairs at a Pelican Crossing: A Case Study in Kuala Lumpur
}

\author{
Nursitihazlin Ahmad Termida ${ }^{1,2, *}$, Munzilah Md Rohani ${ }^{1,2}$, Basil David \\ Daniel $^{1,2}$, Noorliyana Omar ${ }^{1,2}$, Dimas Bayu Endrayana Dharmowijoyo ${ }^{3}$
}

${ }^{1}$ Faculty of Civil and Environmental Engineering, Universiti Tun Hussein Onn Malaysia, 86400 Johor, MALAYSIA

${ }^{2}$ Smart Driving Research Centre, Faculty of Civil and Environmental Engineering, Universiti Tun Hussein Onn Malaysia, 86400 Johor, MALAYSIA

${ }^{3}$ Department of Civil and Environmental Engineering, Faculty of Engineering, Universiti Teknologi Petronas, 32610 Perak, MALAYSIA

*Corresponding Author

DOI: https://doi.org/10.30880/ijie.2019.11.01.027

Received 15 July 2018; Accepted 12 December 2018; Available online 15 May 2019

\begin{abstract}
Pedestrian accidents are a serious problem in Malaysia, especially child pedestrians. Over the past decade, pedestrian fatalities in Malaysia were ranked third after car and motorcycle related fatalities, in which $40 \%$ of the casualties involved children aged 6 to 10 years old. To date, however, little are known about children's behaviour in actual traffic environments, and their behaviours when they are accompanied by adults while crossing the roads. The present study is intended to fill this gap by observing the behaviours of 98 adult-child pairs as they crossing the roads on Pedestrian Light Controlled Crossing (Pelican) type at an urban signalised intersection in Kuala Lumpur. Eight behaviours were coded: crossing in the crosswalk, stopping at the kerb, parents giving oral instructions to the child, pressing the button, waiting for the 'Green man', looking at both directions before crossing, holding hands, and walking (not running) while crossing. The results show that adults set a good example to the children on how to cross the Pelican crossing safely, but they are not taking this advantage to educate their children regarding the crossing behaviour. They also seem to show that 10 -year old children can be trusted to conduct safe crossing behaviour, and/or can be educated on how to cross the roads safely. The only gender difference to emerge revealed that girls are more likely to walk while crossing as compared to boys. Several age differences are significantly affect children crossing behaviours.
\end{abstract}

Keywords: Pedestrian behaviour, child pedestrians, Pelican crossings, crossing behaviour, Kuala Lumpur

\section{Introduction}

Pedestrian safety is one of the main concern globally especially among children [1,2,3] and elderly [4] due to their physical limitations and lower cognitive abilities compared to adults [5,6]. According to the statistics of road accident deaths in Malaysia, pedestrian fatalities ranked third highest after car and motorcycle fatalities for the year 2008 until 2017 [7]. On average, 562 pedestrians are killed per year on Malaysian roads in which $40 \%$ of pedestrian casualties involved children aged between 6 to 10 years old [8]. Numerous studies have found that child pedestrians are at high risk when they cross the road $[1,2,9,10,11]$. To tackle this problem, various knowledge-based training programmes related to pedestrian safety have been implemented (e.g. the Green Cross Code). The programmes nowadays have 
shifted toward practical training in real traffic environments [1]. To date, however, little are known about children's behaviour in actual traffic environments and their behaviours, when they are accompanied by adults while crossing the roads. The present study is intended to fill this gap by observing the behaviours of adult-child pairs as they crossing the roads on Pedestrian Light Controlled Crossing (Pelican) type at an urban signalised intersection. It is worth noting that studies related to pedestrian behaviour at signalised intersection in Malaysia are still limited [10].

Children crossing behaviour are uncertain. Previous scholars have argued that their crossing behaviour are related to age, resulting in inability to correctly assess traffic conditions [12], inconsistency in their behaviour and judgement [13], and their attitudes toward traffic situations [9]. For example, five-year-olds believe that as road users, they should avoid damaging things. Meanwhile, older children believe that as road users, they should avoid making mistakes that could lead to road accidents [13]. This shows that children in different age groups have different perceptions on road users' responsibilities which result in different decisions on how to behave appropriately on the roads. Therefore, older children have much better understanding on appropriate road behaviours that are related to road safety, thus can avoid errors and mistakes that may lead to damage and accidents. Previous studies have proved that children between the aged of 5 to 9 years old are the most vulnerable and prone to road accidents four times more than adults $[1,14,15]$.

Apart of age effects, gender may also affect children crossing behaviour. To date, studies on the effects of gender on pedestrian casualties are more focused on adults, but not children. For example, it is found that men pedestrian have higher involvement in road accidents than their counterparts $[16,17,18]$. Another study done in Malaysia on observing pedestrian crossing behaviour at urban signalised intersection has found that men often started crossing the roads randomly and tend to execute dangerous crossing at signalised intersection [10]. On the contrary, one study found that males tend to be more cautious when attempting to cross roads as they were found to accept larger gaps in traffic when crossing roads [19]. Therefore, gender effects on children crossing behaviour need to be investigated since there is limited knowledge on this effect.

Children crossing behaviour are different when they cross the roads accompanied by adults. An unobtrusive observational study done on 269 children ages between 7 to 11 years old in Israel found that children crossing with an adult committed more unsafe behaviour compared to children crossing without an adult. In addition, children who were not holding hands with their adult companions committed more unsafe behaviours than children who were holding hands with their adult companions while crossing the roads [9]. These results seem to support the results found by Zeedyk and Kelly [1] that parents are not taking opportunities to teach and educate their children on how to cross the roads in actual traffic environments especially at lighted crosswalk setting such as Pelican Crossing. Parents tend to dominant the crossing behaviour in which they are the one who checked for the traffic (by looking left and right) and pressed the crossing button, instead of teaching their children on how to cross the roads safely. These resulting in careless road-crossing behaviour on the child's part [1]. This is quite surprising since parents are expect to give an early education for their children since they are having a primary responsibility to teach their children about life including road safety. A survey done in the U.K. on 2000 parents found that the participants see themselves as the main providers to their children in giving road safety education [20].

The present study, therefore, was aimed to add some knowledge on the adult-child pairs' behaviour while crossing a Pelican crossing type at signalised intersection in urban areas by documenting their behaviours. Note that pedestrian violations associated with pedestrian accidents are higher at signalised intersection than other crossing facilities [21]. Furthermore, different crossing behaviour displayed as a result of child gender and age were also observed. The limitation is that the study was not fully categorised as unobtrusive observational study since it was also involved interview sessions with the parents after the participants crossing the roads safely. However, it is assumed that the crossing style and behaviour of the participants were not being obstructed since they did not know that they were being observed from they started to cross the Pelican crossing until they have crossed it safely. The results were hoped to be useful in improving or enhancing existing policies and/or educational programmes and campaigns with regard to road crossing safety especially involving children pedestrian. Thus, reducing pedestrian casualties in the future.

\section{Method}

The method in collecting data for this study is similar to Zeedyk and Kelly [1], but with an additional approach (i.e. interview) and with the help of tools (i.e. video camera). The participants involved in this study has similar characteristics to Zeedyk and Kelly [1] in order to achieve the objectives of the study.

\subsection{Participants}

The definition of adult-child pair in this study is a couple of matured person with a child whose age is under 11 years old. Thus, this study only focused on adult-child pairs with a single child. As for the child's age, the argument is that $40 \%$ of pedestrian casualties in Malaysia were involving children with the aged between 6 to 10 years old [8]. While the argument for choosing the adult-child pairs with a single child is to provide a more consistent basis for drawing interpretations of the results [1]. Hence, participants consisted of 98 child-adult pairs who crossed the Pelican crossing during observational periods are used for this study purposes. As for the child's gender, $56.1 \%$ out of 98 children are girls. Fig. 1 shows the percentage of child participants involved in this study according to their age. It can 
be seen that the highest number of participants involved in this study are among children with the ages of 3 and 8 years old with $16.3 \%$. Meanwhile the lowest number of participants are children with the age of 2 years old which representing only $1.0 \%$ from the full sample. This is because most of the children with the age of 2 years old and below still need fully guidance and attention by their parents on every movements they make including crossing the roads. As expected, there are no child participant with the age of 1 year old and below since most of them are carried in baby stroller or baby carriers by their parents. It is noted that the child's age distribution in this study may not representing the total population. However, this study aimed to documenting the adult-child pairs behaviours related to crossing behaviour due to the fact that this knowledge are still limited particularly in Malaysia. Thus, the need of obtaining the data to represent the whole population is not the main goal in this study.

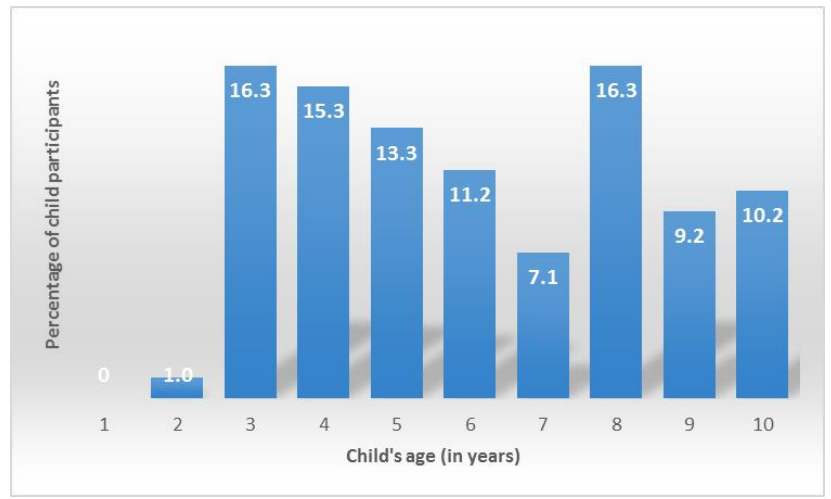

Fig. 1 - The percentage of child participants according to their age categories $(N=98)$

All the participants have full opportunities to portray all the coded behaviours. Only the data from adult-child pairs that have clear visions throughout the crossing captured by video cameras were included in the analysis. It is possible that some of them will be observed more than once during the study period due to the fact that they are randomly chosen and anonymous. However, the chance is probably low because the data were captured only for two days and this will be explained later.

\subsection{Procedure}

\subsubsection{Observation Location}

Observations were conducted in one of the main signalised intersection in Kuala Lumpur metropolitan city centre, namely Jalan Sungai Wang - Jalan Sultan Ismail intersection $\left(3^{\circ} 08^{\prime} 48.3^{\prime \prime N}, 101^{\circ} 42^{\prime} 40.7^{\prime \prime E}\right)$ as shown in Fig. 2 . Jalan Sungai Wang has three lanes, while Jalan Sultan Ismail is a single carriageway (four lanes) divided by a median. The light railway transit (LRT) line and station is situated above the median, thus the median is considered very wide. The pedestrian crossing type is a Pelican crossing as mentioned previously. There were four Pelican crossings involved in this study. Based on the early visual observations, the number of pedestrians using this Pelican crossing is quite high, including the number of adult-child pairs. Moreover, this intersection is located in the so-called 'Golden Triangle' areas in Kuala Lumpur that is representing one of the hot spots of tourists' attraction.

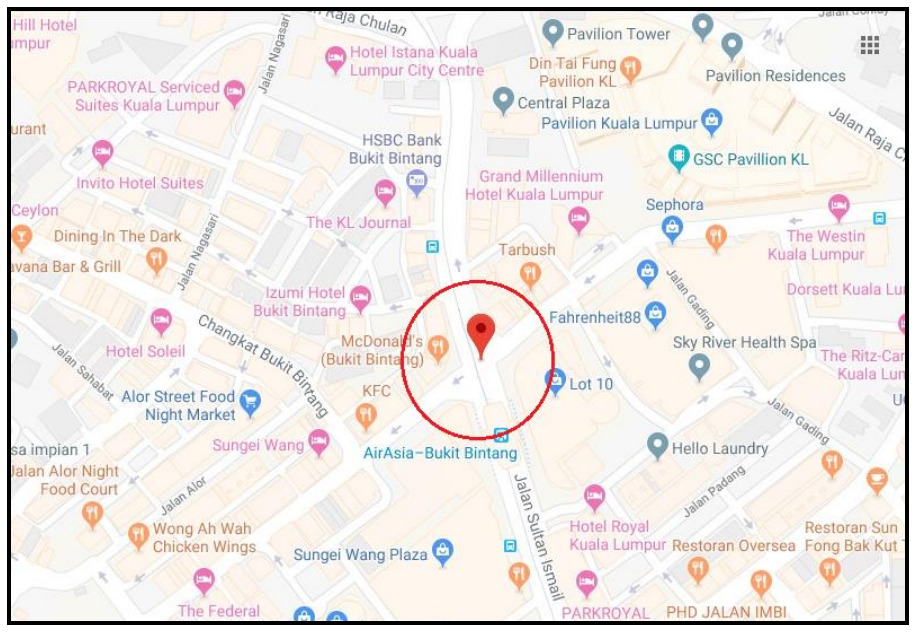

Fig. 2 - Site location of the study 


\subsubsection{Observation and Data Collection Method}

The behaviours of adult-child pairs crossing were observed using video recording. Zeedyk et al. [20] have argued that video recording that are taken while children crossing the roads is the best method to code children specific behaviours that are relevant to each type of crossing. Moreover, it does not need high number of labours or observers to collect the data compared to unobstrusive observational method [1,9]. On the other hand, this video recording method may obstruct the pedestrians if they are aware about the video camera capturing them crossing the roads, thus may affect their crossing behaviour. However, since the number of pedestrians are quite high in the study location, it is logical to assume that the pedestrians may not noticed about them being recorded by the observer while they are crossing the roads. Thus, the video recording method was chosen. The observations were conducted in two days in weekend (Saturday and Sunday) from 2:00 p.m. to 4:00 p.m. since the number of pedestrian is high at that hour and during weekends compared to weekdays, according to the early observations by the observer. Each Pelican crossings were observed for half an hour per day. Hence, the observations were took about four hours in two days. Fig. 3 illustrates the location of video cameras at the study location. Two video cameras were used in this study in which each of them captured participants crossing at least two Pelican crossings.

Apart of the video recording, this study also conducted a simple interview. The interview was done on the parents or adults accompanying a child when they already crossed the Pelican crossing safely. Thus, it is assumed that their crossing behaviours were not being disturbed and obstructed by the interview session since it was done after they crossed the roads. Only one question was asked by the observer in order to know the child's actual age.

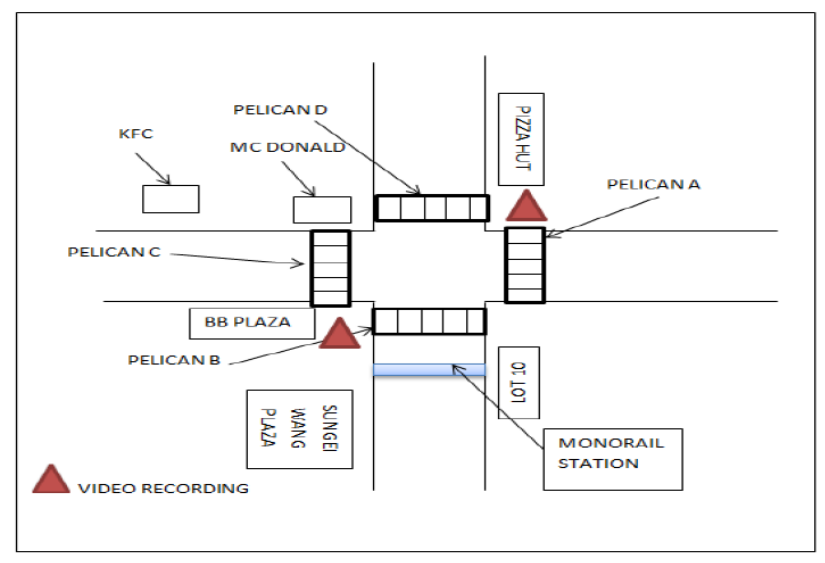

Fig. 3- The location of video cameras at the study location

\subsubsection{Behaviours Coded}

Similar to Zeedyk and Kelly [1], there are eight different elements of the road crossing monitored and coded on the adult-child pairs in this study. The eight behaviours consist of: (1) crossing within the marked crosswalk, (2) stopping at the kerb, (3) adult giving oral instructions to the child, (4) pressing the button to operate the lights, (5) waiting for the 'green man' to appear before beginning to cross, (6) checking for approaching traffic by looking left and right before crossing, (7) holding hands while crossing, and (8) walking (not running) across the road. Zeedyk and Kelly [1] have argued that these eight behaviours are considered ideal for adults crossing the road with young children at marked pedestrian crossing (i.e. Pelican crossing). From other perspective, it is thought that these eight behaviours can be the safest behaviours for child pedestrians to cross the Pelican crossing type if they comply each of the behaviours.

The presence or absence of each behaviour are coded. All the behaviours are coded for the adult-child pairs as a unit, but with two exceptions: 'pressing the button' and 'looking at both directions before crossing' behaviours. For these two behaviours, it is coded separately for adults and children. Since the observer could not stand near to the participants during the observations, therefore, the third (3) behaviour of 'adult giving oral instructions to the child' is coded as presence whenever the video recording captured that the parents or adults talking to the child before they (either adult or child) pressing the button to operate the crossing light, regardless of the contents of their communication.

\section{Results and Discussion}

This study aimed to shed some light on the adult-child pairs behaviour while crossing the marked crossing by documenting eight behaviours throughout the crossing process in the real traffic situations. These data will be presented 
first. It will then be followed by the comparison analysis using Chi-Square $\left(\chi^{2}\right)$ in order to determine whether different behavioural patterns were displayed as a result of either child's age and gender.

\subsection{Frequency of Behaviours Portrayed by Full Sample}

Table 1 shows the percentage of child participants following each behaviour coded based on gender. This includes the percentage of adults complied with the 'pressing the button' and 'looking at both directions before crossing' behaviours. The most complied behaviour by the children participants are 'stopping at the kerb' and 'holding hands' behaviours with 100\% compliance. Then followed by the 'crossing in the crosswalk' and 'walking (not running) while crossing' behaviour with $99 \%$ and $95.9 \%$ compliance respectively. As for the 'waiting for the 'Green man' behaviour, $81.6 \%$ children complied with the behaviour. These results indicate that parents or adults accompanying children to cross the Pelican crossing in this study set good examples to their children with regard to crossing behaviour, thus resulting in a well-behave crossing behaviour among their children. Moreover, more than $75 \%$ parents or adults in this study pressing the button themselves to operate the crossing light and looking for the traffic before crossing to ensure the road is safe enough for them to cross. Therefore, these results is in-line with previous study done in city of Dundee, Scotland [1]. This revealed that children in this study trusted and relied on their parents to cross the roads.

However, it is also found that only few parents or adults in this study took these opportunities to educate their children on how to cross the roads safely in the real situations; with only $38.8 \%$ (about 38 adults) of them have been recorded giving instructions to their children. This is similar to the finding found by Zeedyk and Kelly [1] but with much higher percentage. Note that they have found only 6\% adults (out of 123 participants, which equivalent to 7 adults) spoken to their children on how to cross the roads. The underlying reasons of these findings are still open for debate. However, although not all the parents or adults in this study educating their children on how to cross the road safely, the children participants in this study are considered well-behave with regard to the crossing behaviour. This is contrast with the study done by Rosenbloom et al. [9] in Israel where they found that children accompanied by adults to cross the roads tend to make careless mistakes, thus resulting in more unsafe behaviours compared to the children that are crossing alone. This could be due to the child age effects in which their participants are children with the ages between 7 to 11 years old. Meanwhile in this study, the child participants were ages below 11 years old.

Table 1 - The percentage of child participants and their gender according to each behaviour coded $(N=98)$

\begin{tabular}{|c|c|c|c|c|c|}
\hline \multirow{2}{*}{ Behaviours } & \multicolumn{2}{|c|}{ Child's gender } & \multirow{2}{*}{ Total } & \multicolumn{2}{|c|}{ Participant } \\
\hline & Boys & Girls & & Child & Adult \\
\hline Crossing in the crosswalk & 42.9 & 56.1 & 99.0 & NA & NA \\
\hline Stopping at the kerb & 43.9 & 56.1 & 100.0 & NA & NA \\
\hline $\begin{array}{l}\text { Parents giving oral } \\
\text { instructions to the child }\end{array}$ & 20.4 & 18.4 & 38.8 & NA & NA \\
\hline Pressing the button & 10.2 & 11.2 & 21.4 & 21.4 & 78.6 \\
\hline $\begin{array}{l}\text { Waiting for the 'Green } \\
\text { man' }\end{array}$ & 36.7 & 44.9 & 81.6 & NA & NA \\
\hline $\begin{array}{l}\text { Looking at both directions } \\
\text { before crossing }\end{array}$ & 3.1 & 3.1 & 6.1 & 6.1 & 87.8 \\
\hline Holding hands & 43.9 & 56.1 & 100.0 & NA & NA \\
\hline $\begin{array}{l}\text { Walking (not } \\
\text { running) while crossing }\end{array}$ & 41.8 & 54.1 & 95.9 & NA & NA \\
\hline
\end{tabular}

Meanwhile, the least complied behaviour by the children participants among these eight coded behaviours is 'looking at both directions before crossing' behaviour with only about $6 \%$ compliance. This is expected since children normally assumed that vehicles must totally stop when the 'Green man' shows up and they do not need to look on the left and right to check for the traffic. Previous study have found that children's road crossing judgement tend to rely on 
partial information and not take any other critical factors into consideration such as whether the pedestrian's or driver's view of the road was blocked [9]. However, this ability to judge whether the road is safe to cross is develop as the children become much older. Some studies have found that by around age 11, children begin to portray their judgement on what consider road dangers [22,23]. Moreover, they trusted their parents or accompanying adults to check the traffic conditions whether it is safe or not to cross as mentioned previously.

\subsection{Frequency of Behaviours Portrayed by Full Sample}

Fig. 4 illustrates the percentage of child participants based on age for each behaviour coded. Based on this figure, it clearly shows that children in this study mostly skip these two crossing behaviours: 'looking at both directions before crossing' and 'pressing the button'. It is worth noting that the parents or adults are mostly conduct these two behaviours as explained in the previous section (see Table 1). It is found that none of the children below 7 years old has assessed the traffic movements by looking on the left and right before crossing in order to ensure whether it is safe to cross. This is parallel to the argument by previous scholars that children judging skills on what considered dangerous on roads are low and develop with age [12,13]. Moreover, parents or adults in this study have dominantly the crossing behaviour in which themselves push the button to operate the lights and gazing to the left and right before crossing, without instructing their children to do the same behaviour. Thus, the young children (i.e. age below 7 years old) may feel that they do not have to do the same behaviour of 'looking at both directions before crossing' since their parents already did that for them.

In comparison, it is found that children ages between 5 and 6 years old are the most committed to all crossing behaviours except for 'pressing the button' and 'looking at both directions before crossing' behaviours. Note that the 'parents giving oral instructions to the child' behaviour is excluded in this case. It means that children at this age range intend to rely on their parents or accompanying adults to cross the roads by holding hands. Note that $100 \%$ of the child participants were holding hands while crossing (see Table 1).

Interestingly, children ages between 7 to 9 years old are less instructed by their parents or accompanying adults compared to other children including children with the age of 10 years old. It is expected that parents will give more attention to much younger children (i.e. below 7 years old), but in this case, parents or accompanying adults also seem to pay more attention to much older children (i.e. 10 years old) instead towards younger children (i.e. 7 to 9 years old). However, it is hard to confirm whether the results will be consistent if more participants are involved. This is also open for debate.

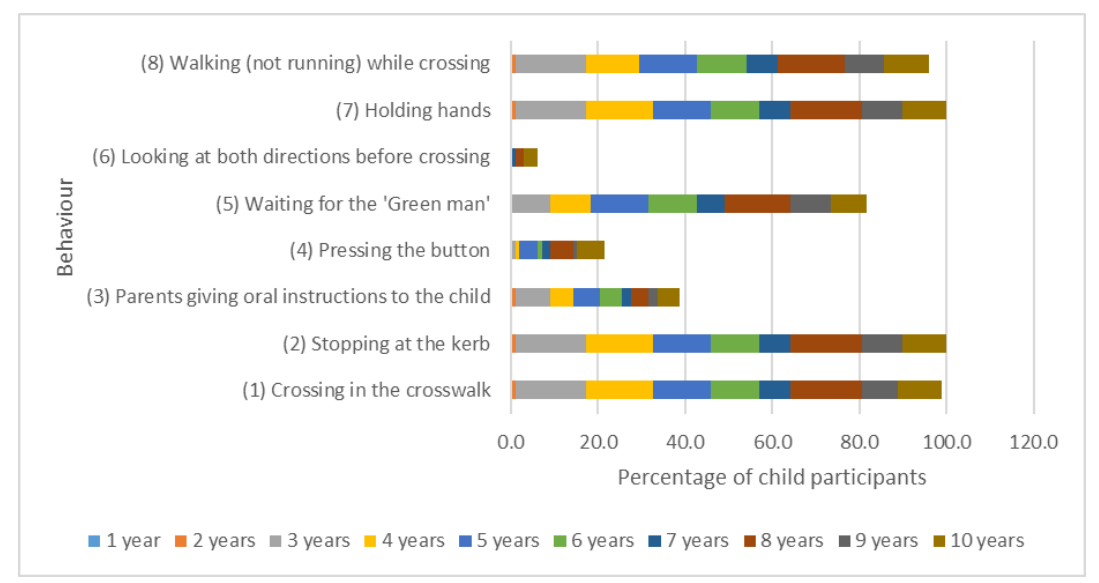

Fig. 4 - The percentage of child participants based on age for each behaviour coded $(N=98)$

\subsection{Child Gender Differences}

A series of Chi-square $\left(\chi^{2}\right)$ analysis were conducted in order to determine the differences in behaviours displayed by pairs with boys and pairs with girls, as shown in Table 2 . It can be seen that the only behaviour that illustrates a significant different as displayed by child gender was 'walking (instead of running) while crossing' behaviour. The relationship between the behaviour and child gender was significant: $\chi^{2}(1, N=98)=5.33, \rho<.05$. The association, however, was of very low strength: $\varphi=.23$ and thus the child gender accounted for only $5.3 \%$ of the variance in the number of children that were walking (instead of running) while crossing the Pelican crossing. This indicates that girls (100\%) are more likely to walk while crossing the Pelican crossing as compared to boys (90.7\%). It is noted that boys have greater tendency to play in the street than girls [24]. Therefore in this case, it seems that boys are more excited to cross the marked crossing and more likely to play while crossing (i.e. running) although their parents or accompanying adults were holding their hands. On the other hand, this could be due to their parents' or accompanying adults' walking 
paces that much faster than others, forcing the children to run to catch up with their walking paces. However, this cannot being confirmed since the participants' walking speeds are not being measured, thus worth for future research.

Table 2 - Chi-square results for each behaviour displayed by child gender

\begin{tabular}{|c|c|c|c|c|}
\hline Behaviour & $\begin{array}{l}\text { Boys } \\
\text { Percentage }^{1}\end{array}$ & $\begin{array}{l}\text { Girls } \\
\text { Percentage }^{2}\end{array}$ & $p$-value & $(\varphi)$ \\
\hline Crossing in the crosswalk & 97.7 & 100.0 & .256 & .11 \\
\hline Stopping at the kerb & 100.0 & 100.0 & $\mathrm{Na}$ & $\mathrm{Na}$ \\
\hline $\begin{array}{l}\text { Parents Giving oral } \\
\text { instructions to the child }\end{array}$ & 44.2 & 34.6 & .331 & .10 \\
\hline Pressing The button & 18.6 & 23.6 & .547 & .06 \\
\hline Waiting for the Green Man & 83.7 & 80.0 & .637 & .05 \\
\hline $\begin{array}{l}\text { Looking at both directions } \\
\text { before crossing }\end{array}$ & 7.0 & 5.5 & .755 & .03 \\
\hline Holding hands & 100.0 & 100.0 & $\mathrm{Na}$ & $\mathrm{Na}$ \\
\hline $\begin{array}{l}\text { Walking (not running) } \\
\text { while crossing }\end{array}$ & 90.7 & 100.0 & $.021 *$ & .23 \\
\hline \multicolumn{5}{|c|}{$\begin{array}{l}{ }^{1} \text { Percentage is calculated over the total number of boys in the full sample }(N=43) \text {. } \\
{ }^{2} \text { Percentage is calculated over the total number of girls in the full sample }(N=55) \text {. } \\
\text { 'Na' means not available. } \\
{ }^{*} p \text {-value }<.05\end{array}$} \\
\hline
\end{tabular}

\subsection{Child Age Differences}

A series of Chi-square $\left(\chi^{2}\right)$ analysis was performed in order to determine whether there are differences in behaviours displayed by pairs with different age of accompanied child. The full results are shown in Table 3 and Table 4. Several behaviours are found to be significantly different for differences in child's age.

It is found that 'crossing in the crosswalk' behaviour was significantly different for 9 years old children compared to other children: $\chi^{2}(1, N=98)=9.99, \rho<.005$. The association, however, was of low strength: $\varphi=.32$ and thus the child of age 9 years old accounted for only $10.2 \%$ variance in the number of children that were crossing in the crosswalk. This indicates that 9-year old children in this study are more likely to commit unsafe behaviour by crossing the roads outside the marked crosswalk compared to other children. However, it is worth noting that only one child aged 9-year old performed the unsafe behaviour that contributes to this result. Therefore, further research with higher samples need to be conducted in the future to confirm this result. Note that previous study on assessing pedestrian crossing behaviour at one of the signalised intersection in Kuala Lumpur found that only $20 \%$ out of 239 pedestrians started crossing outside the marked crosswalk [10]. This indicates that not so many pedestrians cross the signalised intersection roads outside the marked crossing, at least in Kuala Lumpur.

As for 'pressing the button' behaviour, children with the age of 10 years old illustrates different behaviour than other children: $\chi^{2}(1, N=98)=9.84, \rho<.005$. The association between the behaviour and the children aged 10 years old was of low strength: $\varphi=.32$ and only accounted for $10.2 \%$ variance in the number of children that were pressing the button to operate the lights. This indicates that 10 -year old children in this study are more likely to push the button compared to younger children. There is one possible explanation on this in which, the parents or accompanying adults may feel that it is the right time for them to trust and educate their children at this age to perform safe crossing behaviour independently by allowing them to push the button to operate the lights.

The 'waiting for the 'Green man' behaviour was found to be significantly different for children with the age below 5 years old $\left(2,3\right.$ and 4 years old). The result was: $\chi^{2}(1, N=98)=4.49, \rho<.05$ for the behaviour and children with the age of 2 years old. The association between the "waiting the 'Green man' behaviour and the children aged 2 years old was considered very low: $\varphi=.21$ and thus accounted for only $4.4 \%$ variance in the number of children that were waiting for the 'Green man' to cross the Pelican crossing. Meanwhile, the result for the same behaviour was significantly different for children aged 3 years old: $\chi^{2}(1, N=98)=8.22, \rho<.005$. The association was of low strength: $\varphi=.29$ and thus accounted for $8.4 \%$ variance in the number of children that were waiting for the 'Green man' to cross the roads. The association result between the behaviour of 'waiting for the 'Green man'" and the children aged 4 years old was significant: $\chi^{2}(1, N=98)=5.53, \rho<.05$. The association was considered very low with $\varphi=.24$ and thus accounted for only $5.8 \%$ variance in the number of children that were waiting for the 'Green man' to cross the roads. These results mean that children below 5 years old in this study tend to not waiting for the 'Green man' to appear before crossing. In other words, they are more likely to start crossing the roads after their parents or accompanying adults push the button to operate the lights. This is expected since younger children (i.e. age below 5 years old) are less mature and have low ability to assess and judge the traffic conditions compared to much older 
children as argued by previous scholars [5-6, 9, 12-13]. In this case, the parents or accompanying adults have portrayed a good example by holding their children hands during the crossing process. Note that $100 \%$ of the parents or accompanying adults in this study held their children hands to cross the Pelican crossing.

The relationship between 'looking at both directions' behaviour and the children aged 10 years old was significant: $\chi^{2}(1, N=98)=11.05, \rho<.005$. The association, however, was of low strength: $\varphi=.34$ and thus accounted for $11.6 \%$ variance in the number of children who were looking at both directions before crossing the Pelican crossing. Again, similar to the argument for 'pressing the button' behaviour, parents or accompanying adults in this study seem to acknowledge that they should start to educate their children at this age on how to cross the roads safely. In other perspective, the parents or accompanying adults in this study also seem to assume that children at the age of 10 years old can be trusted to conduct the safe crossing behaviour by allowing them to be independently looking for the traffic before crossing.

Table 3 - Chi-square results for each behaviour displayed by child age from 1 to 5 years old

\begin{tabular}{|c|c|c|c|c|c|}
\hline \multirow[t]{2}{*}{ Behaviour } & \multicolumn{3}{|c|}{ Child age in years $(N=98)$} & \multirow[b]{2}{*}{$4(n=15)$} & \multirow[b]{2}{*}{$5(n=13)$} \\
\hline & $1(n=0)$ & $2(n=1)$ & $3(n=16)$ & & \\
\hline \multicolumn{6}{|c|}{ Crossing in the crosswalk } \\
\hline Number of children & 0 & 1 & 16 & 15 & 13 \\
\hline Percentage $^{1}$ & 0 & 100 & 100 & 100 & 100 \\
\hline$p$-value & $\mathrm{Na}$ & .919 & .657 & .669 & .694 \\
\hline $\operatorname{Phi}(\varphi)$ & $\mathrm{Na}$ & .01 & .04 & .04 & .04 \\
\hline \multicolumn{6}{|l|}{ Stopping at the kerb } \\
\hline Number of children & 0 & 1 & 16 & 15 & 13 \\
\hline Percentage $^{1}$ & 0 & 100 & 100 & 100 & 100 \\
\hline$p$-value & $\mathrm{Na}$ & $\mathrm{Na}$ & $\mathrm{Na}$ & $\mathrm{Na}$ & $\mathrm{Na}$ \\
\hline Phi $(\varphi)$ & $\mathrm{Na}$ & $\mathrm{Na}$ & $\mathrm{Na}$ & $\mathrm{Na}$ & $\mathrm{Na}$ \\
\hline \multicolumn{6}{|c|}{ Parents giving oral instructions to the child } \\
\hline Number of children & 0 & 1 & 8 & 5 & 6 \\
\hline Percentage $^{1}$ & 0 & 100 & 50.0 & 33.3 & 46.2 \\
\hline$p$-value & $\mathrm{Na}$ & .207 & .314 & .638 & .558 \\
\hline Phi $(\varphi)$ & $\mathrm{Na}$ & .13 & .10 & .05 & .06 \\
\hline \multicolumn{6}{|l|}{ Pressing the button } \\
\hline Number of children & 0 & 0 & 1 & 1 & 4 \\
\hline Percentage $^{1}$ & 0 & 0 & 6.3 & 6.7 & 30.8 \\
\hline$p$-value & $\mathrm{Na}$ & 600 & .106 & .130 & .378 \\
\hline Phi $(\varphi)$ & $\mathrm{Na}$ & .05 & .16 & .15 & .09 \\
\hline \multicolumn{6}{|c|}{ Waiting for the 'Green man' } \\
\hline Number of children & 0 & 0 & 9 & 9 & 13 \\
\hline Percentage $^{1}$ & 0 & 0 & 56.3 & 60.0 & 100 \\
\hline$p$-value & $\mathrm{Na}$ & $.034 *$ & $.004 * *$ & $.019 *$ & .066 \\
\hline Phi $(\varphi)$ & $\mathrm{Na}$ & .21 & .29 & .24 & .19 \\
\hline \multicolumn{6}{|c|}{ Looking at both directions before crossing } \\
\hline Number of children & 0 & 0 & 0 & 0 & 0 \\
\hline Percentage $^{1}$ & 0 & 0 & 0 & 0 & 0 \\
\hline$p$-value & $\mathrm{Na}$ & .797 & .264 & .282 & .323 \\
\hline Phi $(\varphi)$ & $\mathrm{Na}$ & .03 & .11 & .11 & .10 \\
\hline \multicolumn{6}{|l|}{ Holding hands } \\
\hline Number of children & 0 & 1 & 16 & 15 & 13 \\
\hline Percentage $^{1}$ & 0 & 100 & 100 & 100 & 100 \\
\hline$p$-value & $\mathrm{Na}$ & $\mathrm{Na}$ & $\mathrm{Na}$ & $\mathrm{Na}$ & $\mathrm{Na}$ \\
\hline Phi $(\varphi)$ & $\mathrm{Na}$ & $\mathrm{Na}$ & $\mathrm{Na}$ & $\mathrm{Na}$ & $\mathrm{Na}$ \\
\hline \multicolumn{6}{|c|}{ Walking (not running) while crossing } \\
\hline Number of children & 0 & 1 & 16 & 12 & 13 \\
\hline Percentage $^{1}$ & 0 & 100 & 100 & 80.0 & 100 \\
\hline$p$-value & $\mathrm{Na}$ & .836 & .367 & $.001 * *$ & .425 \\
\hline Phi $(\varphi)$ & $\mathrm{Na}$ & .02 & .09 & .34 & .08 \\
\hline
\end{tabular}

${ }^{1}$ Percentage is calculated over the total number of children in for each age categories.

'Na' means Not available.

$* p$-value $<.05, * * p$-value $<.005$. 
The relationship between 'walking instead of running while crossing' behaviour and the children aged 4 years old was significant: $\chi^{2}(1, N=98)=11.46, \rho<.005$. The association was of low strength with $\varphi=.34$ and thus accounted for $11.6 \%$ variance in the number of children who were walking while crossing the Pelican crossing. This means that 4-year old children in this study are tend to running while crossing the Pelican crossing compared to other children. This finding is similar with Zeedyk and Kelly [1] that found that 50\% of children ran across the marked crossing although they were holding hands. However, in this study, the percentage is much lower (20\%) than their study. The argument made by Zeedyk and Kelly can be applied in this case in which some parents or accompanying adults may have much faster walking pace that force the children to run in order to follow their parents' or adult companions' walking paces.

Table 4 - Chi-square results for each behaviour displayed by child age from 6 to 10 years old

\begin{tabular}{|c|c|c|c|c|c|}
\hline \multirow[t]{2}{*}{ Behaviour } & \multicolumn{5}{|c|}{ Child age in years $(N=98)$} \\
\hline & $6(n=11)$ & $7(n=7)$ & $8(n=16)$ & $9(n=9)$ & $10(n=10)$ \\
\hline \multicolumn{6}{|c|}{ Crossing in the crosswalk } \\
\hline Number of children & 11 & 7 & 16 & 8 & 10 \\
\hline Percentage $^{1}$ & 100 & 100 & 100 & 88.9 & 100 \\
\hline$p$-value & .721 & .780 & .657 & $.002 * *$ & .735 \\
\hline Phi $(\varphi)$ & .04 & .03 & .04 & .32 & .03 \\
\hline \multicolumn{6}{|l|}{ Stopping at the kerb } \\
\hline Number of children & 11 & 7 & 16 & 8 & 10 \\
\hline Percentage $^{1}$ & 100 & 100 & 100 & 100 & 100 \\
\hline$p$-value & $\mathrm{Na}$ & $\mathrm{Na}$ & $\mathrm{Na}$ & $\mathrm{Na}$ & $\mathrm{Na}$ \\
\hline Phi $(\varphi)$ & $\mathrm{Na}$ & $\mathrm{Na}$ & $\mathrm{Na}$ & $\mathrm{Na}$ & $\mathrm{Na}$ \\
\hline \multicolumn{6}{|c|}{ Parents giving oral instructions to the child } \\
\hline Number of children & 5 & 2 & 4 & 2 & 5 \\
\hline Percentage $^{1}$ & 45.5 & 28.6 & 25.0 & 22.2 & 50.0 \\
\hline$p$-value & .629 & .565 & .216 & .285 & .442 \\
\hline Phi $(\varphi)$ & .05 & .06 & .12 & .11 & .08 \\
\hline \multicolumn{6}{|l|}{ Pressing the button } \\
\hline Number of children & 1 & 2 & 5 & 1 & 6 \\
\hline Percentage $^{1}$ & 9.1 & 28.6 & 31.3 & 11.1 & 60.0 \\
\hline$p$-value & .290 & .633 & .295 & .429 & $.002 * *$ \\
\hline Phi $(\varphi)$ & .11 & .05 & .11 & .08 & .32 \\
\hline \multicolumn{6}{|c|}{ Waiting for the 'Green man' } \\
\hline Number of children & 11 & 6 & 15 & 9 & 8 \\
\hline Percentage $^{1}$ & 100 & 85.7 & 93.8 & 100 & 80.0 \\
\hline$p$-value & .095 & .772 & .171 & .135 & .888 \\
\hline Phi $(\varphi)$ & .17 & .03 & .14 & .15 & .01 \\
\hline \multicolumn{6}{|c|}{ Looking at both directions before crossing } \\
\hline Number of children & 0 & 1 & 2 & 0 & 3 \\
\hline Percentage $^{1}$ & 0 & 14.3 & 12.5 & 0 & 30.0 \\
\hline$p$-value & .369 & .350 & .245 & .421 & $.001 * *$ \\
\hline Phi $(\varphi)$ & .09 & .09 & .12 & .08 & .34 \\
\hline \multicolumn{6}{|l|}{ Holding hands } \\
\hline Number of children & 11 & 7 & 16 & 8 & 10 \\
\hline Percentage $^{1}$ & 100 & 100 & 100 & 100 & 100 \\
\hline$p$-value & $\mathrm{Na}$ & $\mathrm{Na}$ & $\mathrm{Na}$ & $\mathrm{Na}$ & $\mathrm{Na}$ \\
\hline Phi $(\varphi)$ & $\mathrm{Na}$ & $\mathrm{Na}$ & $\mathrm{Na}$ & $\mathrm{Na}$ & $\mathrm{Na}$ \\
\hline \multicolumn{6}{|c|}{ Walking (not running) while crossing } \\
\hline Number of children & 11 & 7 & 15 & 9 & 10 \\
\hline Percentage $^{1}$ & 100 & 100 & 93.8 & 100 & 100 \\
\hline$p$-value & .468 & .571 & .632 & .516 & .491 \\
\hline Phi $(\varphi)$ & .07 & .06 & .05 & .07 & .07 \\
\hline
\end{tabular}

\section{Summary}

This study has shown that children is well-behave in almost all crossing behaviours coded, except for 'looking at both directions' and 'pressing the push button' behaviour that are mostly done by the parents or accompanying adults. 
For these two behaviours, however, it is found that 10-year old children are more likely to conduct the behaviours compared to other children. Thus, these results yield three issues. First, the parents or accompanying adults in this study have set a good example to their children on how to cross the Pelican crossing since above $80 \%$ of the children follow the safe crossing behaviour (with exceptions of two behaviours mentioned previously). Second, the parents or accompanying adults are not taking this advantage to educate their children on how to cross the roads, particularly a Pelican crossing type, similar to Zeedyk and Kelly [1] found in their study. They dominantly assessing the traffic conditions by looking on the left and right sides of the roads before crossing and they are the one who push the button to operate the lights, which instead may be fun to be conducted by the children and in the same time educating them to cross the roads safely. Third, the parents or accompanying adults in this study seem to show that they should educate and trust their children to assess the traffic conditions and pressing the push button at the age of 10 years old. This seems to accord with the arguments by previous studies [22,23] that child around the age of 11 years old begin to show their abilities to assess the traffic conditions whether it is danger or not. However, this is interesting finding since there are no clear age limit in which the parents can allow their children to cross the roads independently as mentioned by Rosenbloom et al. [3]. Note that some studies have recommended that children between the ages of 8 to 10 years old can cross the roads alone $[22,25,26]$. Further research with much higher samples than this study need to be conducted in order to confirm this in the context of Malaysian pedestrians. Moreover, it may also interesting to investigate why children do not learn crossing behaviour through observational training displayed by their parents or accompanying adults. Based on these findings, it is recommended that a basic road safety training programme need to be implemented among the parents in Malaysia so that they realise how important for them to educate their children as early as possible particularly on how to cross the roads safely, thus casualties among child pedestrians can be reduced. It is worth noting that this similar programme has succeeded in increasing the quality of parent teaching efforts in the U.K. [27,28].

\section{References}

[1] Zeedyk, M.S., \& Kelly, L. (2003). Behavioural observations of adult-child pairs at pedestrian crossings. Accident Analysis and Prevention, 35, 771-776.

[2] Morrongiello, B.A., \& Barton, B.K. (2009). Child pedestrian safety: Parental supervision, modeling behaviors, and beliefs about child pedestrian competence. Accident Analysis and Prevention, 41, 1040-1046.

[3] Rosenbloom, T., Sapir-Lavid, Y., \& Hadari-Carmi, O. (2009). Social norms of accompanied young children and observed crossing behaviors. Journal of Safety Research, 40, 33-39.

[4] Avineri, E., Shinar, D., \& Susilo, Y.O. (2012). Pedestrians' behaviour in cross walks: The effects of fear of falling and age. Accident Analysis and Prevention, 44, 30-34.

[5] Schieber, R., \& Vegega, M. (2002). Education versus environmental countermeasures. Injury Prevention: Journal of the International Society for Child and Adolescent Injury Prevention, 8, 10-11.

[6] Musselwhite, C.B.A. (2006). Prolonging safe driving behaviour through technology: Attitudes of older drivers. 26th International Congress of Applied Psychology (Athens), 16-21.

[7] Road Safety Department of Malaysia (JKJR). (2018). Buku Statistik Kemalangan Jalan Raya. Retrieved on August 26, 2018 from http://www.jkjr.gov.my/ms/muat-turun/func-startdown/136/lang,ms-my/.

[8] Road Safety Department of Malaysia (JKJR). (2017). Kemalangan melibatkan pejalan kaki di Malaysia. Retrieved on August 26, 2018 from http://www.jkjr.gov.my/ms/bilik_media/poster-kempen/kempen-media-sosial2017/keselamatan-pejalan-kaki/3139-kemalangan-melibatkan-pejalan-kaki-di-malaysia.html.

[9] Rosenbloom, T., Ben-Eliyahu, A., \& Nemrodov, D. (2008). Children's crossing behavior with an accompanying adult. Safety Science, 46, 1248-1254.

[10] Hamidun, R., Kordi, N. E., Endut, I. R., \& Ishak, S. Z. (2016). Behavioural observations of crossing pedestrians at urban signalized intersections. Jurnal Teknologi, 78(5-2), 9-14.

[11] Koh, P. P., Wong, Y. D., \& Chandrasekar, P. (2014). Safety evaluation of pedestrian behaviour and violations at signalised pedestrian crossings. Safety Science, 70, 143-152.

[12] Demetre, J.D., Lee, D.N., Pitcairn, T.K., Grieve, R., Thomson, J.A., \& Ampofo-Boateng, K. (1992). Errors in young children's decisions about traffic gaps: Experiments with roadside simulations. British Journal of Psychology, 83, 189-202.

[13] Thornton, S., Pearson, A., Andree, K., \& Rodgers, N. (1999). Taking the child's perspective seriously. Psychologist, 12, 393-394.

[14] Jones, W.R., \& Nguyen, L.B. (1988). Pedestrian accidents in New Zealand. Road Traffic Safety Seminar Papers, 1, (Wellington: New Zealand Road Traffic Safety Research Council).

[15] Zeedyk, M. S., Wallace, L., Carcaty, B., Jones, K., \& Larter, K. (2001). Children and road safety: Increasing knowledge does not improve behavior. British Journal of Educational Psychology, 71, 573-594.

[16] Prato, C. G., Gitelman, V., \& Bekhor, S., (2012). Mapping patterns of pedestrian fatal accidents in Israel. Accident Analysis and Prevention, 44(1), 56-62.

[17] Al-Madani, H., \& Al-Janahi, A., (2006). Personal exposure risk factors in pedestrian accidents in Bahrain. Safety Science, 44(4), 335-347. 
[18] Brosseau, M., Zangenehpour, S., Saunier, N., \& Miranda-Moreno, L., (2013). The impact of waiting time and other factors on dangerous pedestrian crossings and violations at signalized intersections: A case study in Montreal. Transportation Research Part F: Traffic Psychology and Behaviour. 21, 159-172.

[19] Al Bargi, W.A., David Daniel, B., Prasetijo, J., Rohani, M.M. \& Mohamad Nor, S.N. (2017). Crossing Behaviour of Pedestrians Along Urban Streets in Malaysia. MATEC Web of Conference, 107(2017) 08003, 1-10.

[20] Zeedyk, M.S., Carcary, W., \& Wallace, L., (1997). Children's road safety through parents' eyes. Proceedings of the BPS Developmental Psychological Section Conference 1997 (Loughborough).

[21] Li, Y., \& Fernie, G. (2010). Pedestrian behavior and safety on a two-stage crossing with a center refuge island and the effect of winter weather on pedestrian compliance rate. Accident Analysis and Prevention. 42(4), 1156-63.

[22] Demetre, J.D., \& Gaffin, S. (1994). The salience of occluding vehicles to child pedestrians. British Journal of Educational Psychology, 64, 243-251.

[23] Foot, H.C., Tolmie, A., Thomson, J., McLaren, B., \& Whelan, K. (1999). Recognising the hazards. The Psychologist, 12, 400-402.

[24] Evans, D., \& Norman, P. (2003). Predicting adolescent pedestrians' road-crossing intentions: An application and extension of the Theory of Planned Behaviour. Health Education Research, 18(3), 267-277.

[25] Dunbar, G., Hill, R., \& Lewis, V. (2001). Children's attentional skills and road behavior. Journal of Experimental Psychology: Applied, 3, 227-234.

[26] Whitebread, D., \& Neilson, K. (1999). Learning to cross the road: Cognition in action. The Psychologist, 12, 403-405.

[27] Department of the Environment, Transport and the Regions (DETR),(2000). Community Approach to Road Safety Education, (London).

[28] Rothengatter, J.A., (1984). A behavioural approach to improving traffic behaviour of young children. Ergonomics, $27,147-160$. 